\title{
Effects of Pre-Reading Strategies on EFL/ESL Reading Comprehension
}

Kei Mihara

This study focuses on two pre-reading strategies: vocabulary pre-teaching and comprehension question presentation. Researchers have claimed that a vocabulary strategy is less effective than any other pre-reading strategy. This study investigates whether their claim is true of Japanese university students. The purpose of the study is twofold. The first goal is to examine the effects of the two pre-reading strategies; the second is to discuss the relationships between students' English proficiency and their reading comprehension. The participants in the present study were asked to perform a pre-reading strategy, read a passage, and then answer comprehension questions. They read four passages altogether. Three weeks after they read the fourth passage, they were asked to answer a questionnaire. This study indicates that vocabulary pre-teaching is less effective for Japanese students, although students with higher English proficiency outperformed lowerlevel students regardless of which pre-reading strategy they used.

Cette étude se penche sur deux stratégies de pré-lecture : le pré-apprentissage du vocabulaire et la présentation de questions de compréhension. Les chercheurs ont prétendu qu'une stratégie reposant sur le vocabulaire est moins efficace que n'importe quelle autre stratégie de pré-lecture. Nous évaluons dans quelle mesure cette affirmation s'applique aux étudiants d'université japonais. Cette étude a deux objectifs : le premier est d'examiner les effets de deux stratégies de pré-lecture, le deuxième est de discuter des liens entre la compétence des étudiants en anglais et leur compréhension en lecture. On a demandé aux participants à l'étude de compléter une stratégie de pré-lecture, lire un passage et ensuite répondre à des questions de compréhension. Ils ont lu quatre passages en tout. Trois semaines après avoir lu le quatrième passage, ils ont complété un questionnaire. Cette étude démontre que le pré-enseignement du vocabulaire est moins efficace pour les étudiants japonais. Le rendement des étudiants les plus compétents en anglais était supérieur à celui des étudiants moins compétents peu importe la stratégie de pré-lecture employée.

\section{Introduction}

According to schema theory (Rumelhart \& Ortony, 1977), comprehending a text is an interpretive process involving the reader's background knowledge and the text itself. Prior knowledge, which is organized and stored in the reader's mind, is termed schema (plural schemata). The reader tries to activate 
an appropriate schema based on clues provided by the writer in the text. According to this theory, readers can comprehend the text only if they reconstruct its content by relating their own schemata to the new information in the text. Carrell (1983) drew a distinction between formal schemata and content schemata: readers who are familiar with the rhetorical or organizational structure of the text (formal schemata) should understand it; similarly, readers who possess background knowledge of the content area of the text (content schemata) should comprehend its content. Thus to help students activate appropriate schemata, pre-reading strategies are considered useful.

Taglieber, Johnson, and Yarbrough (1988) investigated the effects of three pre-reading strategies on the reading comprehension of Brazilian university students. They argued that vocabulary pre-teaching was significantly less effective than pre-questioning and pictorial context. However, Carrell (1988) claimed, "Pre-teaching vocabulary in order to increase learning from text will be more successful if the words to be taught are key words in the target passage" (p. 243). Hudson (1982) compared two types of pre-reading strategies. One was a pictorial strategy: students were asked to look at a set of pictures, discuss the pictures, and predict what they expected to find in the passage. The other was a vocabulary strategy. He found that the former type of prereading strategy had a greater effect on reading comprehension than the latter, but that the effect was significant only for beginning and intermediate-level students. With advanced-level students, there were no significant differences between the two types of pre-reading strategies.

According to Taglieber et al. (1988), the three pre-reading strategies (pictorial context, vocabulary pre-teaching, and pre-questioning) were intended to help EFL students overcome three major problems that may disrupt reading comprehension. The first is a lack of vocabulary knowledge; another is difficulty in using language cues to meaning; and the third is lack of conceptual knowledge. Unfamiliar words or phrases can interfere with students' comprehension. Pre-teaching vocabulary may help address this vocabulary problem. Students also find it difficult simultaneously to remember earlier textual information and predict what is coming next. The pre-reading strategies of looking at pictures and pre-questioning may help students make predictions.

This study questions the contention that vocabulary pre-teaching is in fact less effective than other options. A pictorial strategy was not investigated because the participants in this study were allowed to use the Internet while they were using the pre-questioning strategy; thus they were able to see pictures on Web sites. In the 1980s, the participants in the above-mentioned studies were not able to use the Internet so their situation was quite different. The use of the Internet is one of the reasons why results from the 1980s should now be challenged. Taglieber et al. (1988) and Hudson (1982) both argued that vocabulary pre-teaching was less effective, but their participants were not Japanese university students. Also, Taglieber et al. investigated 
Brazilian students, and Hudson's (1982) participants were heterogeneous in terms of language background. When Zhang (2008) examined the effects of formal schemata on reading comprehension, her findings differed from those of Sharp (2002), who had studied the same text feature in relation to another group. She said that the reason was that "the subjects in Sharp's study (2002) were Hong Kong Chinese school children (mean age 14.1) while the subjects in this study are sophomores in a mainland China university" (p. 205). This supports the concern that a difference in the participants might lead to different findings. Therefore, the present study was conducted with Japanese students in order to see if there is a difference among nationalities.

\section{Methodology}

The study involved 78 Japanese first-year university students enrolled in three general English classes: 20 students (19 males and 1 female) were in Class A (pre-intermediate level), 27 students (25 males and 2 females) in Class B (pre-intermediate level), and 31 students (29 males and 2 females) in Class C (upper-intermediate level). All were studying in the Faculty of Science and Engineering in a private university in Japan. A variety of students attend this university; some at advanced levels and others at pre-intermediate levels. Therefore, students are required to take a placement test immediately on entry and are placed in a suitable class according to their test results. Students in a pre-intermediate class will have scored 300-350 on the TOEIC, whereas upperintermediate students will have achieved 400-450. English classes are held twice a week for 90 minutes and are compulsory for all first-year students. The participants in the present study were using a textbook published by in Japan similar to New Headway Pre-Intermediate (Soars \& Soars, 2007). Their ages ranged from 18 to 20 .

Four passages and their comprehension questions were extracted from New Headway Pre-Intermediate and used in this study. The four passages were chosen based on the familiarity of the topic to the students. These were Xrays, London, DNA, and Google (Soars \& Soars, 2007), about which the students had the opportunity to read in high school. Therefore, the third of the problems noted by Taglieber et al. (1988), lack of conceptual knowledge, did not apply in this situation. However, there were still two problems: lack of vocabulary knowledge and difficulty in using language cues to meaning. Therefore, this study investigated how the two pre-reading strategies (vocabulary pre-teaching and pre-questioning) helped the students overcome these two problems.

The comprehension questions about X-rays and London were true/false questions, whereas for the DNA and Google passages students were required to write answers in their own words. The pre-reading strategies (vocabulary pre-teaching and pre-questioning) were conducted in a deliberately test-like manner and were marked like reading comprehension tests. Japanese stu- 
dents are likely to complain about being forced to do group activities. They tend to believe that class activities should be serious, and thus they prefer to study individually. Also, university students in Japan often do not have much motivation. If they are asked to use pre-reading strategies as a group task or as a class activity, they will probably not be highly motivated. If pre-reading strategies are used in the form of tests even though the scores do not affect their grades, they will be well motivated to use the strategies.

All the students in the three classes used the two pre-reading strategies. Those in one pre-intermediate class (Class A or B) were first asked to guess the content of the passage from its title. They were then were given a list of key words and phrases from the passage and given five minutes to translate them into Japanese without looking them up in the dictionary. I selected and listed key words and phrases in order. After taking the vocabulary test, participants were taught the meanings of the words and phrases and marked their vocabulary answer sheets themselves. They were then asked to read the passage and answer the questions, which were not in order. Although the comprehension questions about the passage were used without changes, they were shuffled so that the students had to read the passage to the end in order to find the clue to Question 1. However, they were allowed to look at the vocabulary list while reading the passage. The key words and phrases were arranged in order so that looking at the vocabulary list would be helpful to the students. Also, understanding all the key vocabulary before reading the passage might activate their content schemata. Carrell (1988) claimed, "Knowledge of vocabulary entails knowledge of the schemata in which a concept participates" (p. 243). EFL/ESL teachers may possibly sometimes teach vocabulary that they consider generally worth learning rather than always focusing on key words from the passage. In this case, the vocabulary may have had limited value in facilitating students' understanding of a specific passage. As Bransford (2004) has suggested, vocabulary should be chosen to ensure that students will develop or activate their schemata:

Students may have developed partial schemata that are sufficient for understanding some types of statements but not for understanding others. We therefore need a more precise analysis of what it means for students to be "familiar" with the words in a text. (p. 617)

In the Hudson (1982) study, what was taught was not vocabulary considered generally worthy of being learned by ESL students, but words that seemed important to the passage. His study did not demonstrate an effect of the vocabulary strategy on ESL students' understanding. However, as Anderson and Freebody (1981) noted, one of the most consistent findings in L1 reading research has been the high correlation between vocabulary and reading comprehension. Thus pre-teaching vocabulary may be more successful if the 
words to be taught are key words from the target passage. I conducted this study in a similar way to that of Hudson (1982) in the sense that the students learned vocabulary important to the story. The participants carried out the vocabulary strategy and then answered all the comprehension questions within five minutes (or eight minutes for the Google passage, which was the longest). They then submitted both the answer sheet and the vocabulary list. I marked the answer sheets and returned them to each student.

In the vocabulary pre-teaching strategy employed in the Taglieber et al. (1988) study, the students read the sample sentences aloud and predicted the meanings of the words without looking at their L1 equivalents. This manner of vocabulary pre-teaching might be effective, but as Hulstijn (2001) pointed out, "elaborating on a new word's meaning in itself may not suffice to have it available for later access" (p. 276). Using L1 translations is also less laborious for students. Nation (2001) claimed that it was quite wrong to assume that L1 translations should not be used in teaching or testing vocabulary. $\mathrm{He}$ said that using the first-language meaning is like "choosing a simple synonym" (p. 351), although using a second-language definition is more arduous. Therefore, in the present study, L1 translations were used as a vocabulary pre-teaching strategy.

The main limitation of this study was time constraints. Because all the participants would spend roughly the same amount of time on a pre-reading strategy, the vocabulary group did not have sufficient time to see words in diverse contexts. As Aebersold and Field (1997) pointed out with regard to vocabulary pre-teaching as an aid to comprehension, students "need to see a word many times in different contexts before it is learned" (p. 139). Although I tried to make sure that the students would understand the key vocabulary before reading the passage, I did not know whether translating the target words without a context might have affected the results.

On the other hand, the students in the other pre-intermediate classes (Class B or A) were first given a list of comprehension questions to answer after reading the passage. They were asked to guess the answers to the questions by using their background knowledge or checking using the Internet. They were required to write down what they thought were the answers on their answer sheet within five minutes. After submitting the pre-reading strategy answer sheet, they were asked to read the passage, answer the comprehension questions from the information they had gained from the passage within five minutes (or eight minutes for the Google passage), and submit the answer sheet. I marked both answer sheets and returned them to each student.

In the Taglieber et al. (1988) study, the pre-questioning strategy consisted of giving students a one-sentence oral summary of the passage and asking them to formulate some questions that they thought the passage might answer. However, the pre-questioning strategy in this study meant giving stu- 
dents a list of comprehension questions beforehand. Miciano (2002) examined if self-questioning as a reading strategy would help Filipino students improve their comprehension of prose texts in English. The participants in her study were "given a session training in question formulation which ran for two weeks" (p. 212). However, the results of her study indicated that "self-questioning as a strategy in ESL reading may not significantly affect text comprehension" (p. 215). Carrell (1984) stated, "Some texts which have comprehension questions following the passages suggest that these may be used as pre-reading questions" (p. 335). Ajideh (2006) proposed that teachers "can adopt ... reading questions from the comprehension questions that appear in the textbook after the reading selection or in the teachers' manual" (pp. 7-8). He commented as follows.

Some pre-reading activities simply consist of questions to which the reader is required to find answers ... from the text. Traditionally, this type of activity followed the text and was designed to test comprehension, but in more recent materials questions often precede the text and function as scanning tasks. That is the learner reads the text quickly in order to find specific information related to the questions. (p. 6)

In the present study, the comprehension questions following the passages in the textbook were used in a pre-questioning strategy, and the questions were in order. The students were able to answer Question 1 immediately after reading the first few lines. Therefore, by reading all the questions about the passage beforehand, the students were able to predict how the story would develop. Although they did not guess the content of the passage from the title and may not have fully understood the key vocabulary, they did learn the structure of the passage before reading it.

The two pre-intermediate classes (Classes A and B) carried out both prereading strategies. The students in Class A were taught vocabulary beforehand when they read about London and Google, but they were given a list of comprehension questions beforehand when they read about X-rays and DNA. On the other hand, the students in Class B were taught vocabulary beforehand when they read about X-rays and DNA, but were given a list of comprehension questions beforehand when they read about London and Google. The students in the upper-intermediate class (Class C) were asked to perform the same pre-reading strategies as the students in Class A. They were given five minutes to carry out a pre-reading strategy and were then asked to read the passage and answer the comprehension questions in five or eight minutes. The pre-reading strategies used in this study can be found in Appendix A. In universities in Japan, a lesson lasts 90 minutes, and thus the first 10 or 13 minutes were used for this research. The tests for the research were conducted once a week, one passage per week, so that the students would not tire of these activities. So it took four weeks for the students 
to read all the passages. Three weeks after they read the fourth passage, they were asked to answer a questionnaire.

This study investigated both pre-intermediate and upper-intermediate students. Taglieber et al. (1988) said that they confirmed Hudson's (1982) contention that students might use their background knowledge about reading material to override problems they might have with the language. On the other hand, Clarke (1980) stated that such a strategy can be undermined by weak second-language ability, calling such a phenomenon a short circuit effect. Lee and Schallert (1997) also argued that an advanced level of proficiency in a second language was required to be able to make use of reading strategies readily used in a first language. Similarly, Al-Issa (2006) claimed:

Most, if not all, research in this area seems to agree that when students are ... skillful in the decoding features needed to recognize words and recognize how they fit together in a sentence (i.e., possess language schema), they are in a better position to comprehend their assigned reading. (p. 41)

If a pre-reading strategy is successful in activating the students' schemata, their English proficiency might not affect their comprehension test performance. The following hypotheses were therefore formulated.

1. Vocabulary pre-teaching is more effective than pre-questioning.

2. Students with lower English proficiency are able to outperform higherlevel students on reading comprehension tests if they carry out a more effective pre-reading strategy.

\section{Analysis}

I marked the students' reading comprehension tests. To test the above research hypotheses, I analyzed the data statistically by means of an analysis of variance (ANOVA) 4, with Ryan's method. The results shown in Tables 1-11 reject the above two hypotheses. Although the differences in test performance observed across pre-reading strategies and levels of English proficiency are not necessarily statistically significant, it is apparent that the pre-questioning group did perform better on the reading comprehension tests. Examining the results by comparing classes with differing English proficiency shows that the higher-proficiency students performed consistently better than those with lower proficiency.

X-rays

The relevant mean scores and standard deviations of the passage about $\mathrm{X}$-rays for the three classes are given in Table 1. From the mean scores, it can be seen that pre-questioning was more effective than vocabulary pre-teaching. 
Table 1

Table of Analysis of Variance 1

\begin{tabular}{lccc}
\hline & mean & $S D$ & $n$ \\
\hline Class A (pre-intermediate) & 91.000 & 13.379 & 20 \\
Class B (pre-intermediate) & 89.630 & 12.614 & 27 \\
Class C (upper-intermediate) & 97.419 & 6.705 & 31 \\
\hline
\end{tabular}

Classes A and C: pre-questioning.

Class B: vocabulary pre-teaching.

Table 2

Table of Analysis of Variance 2

\begin{tabular}{lrrrrr}
\hline source & SS & $d f$ & MS & $F$ & $p$ \\
\hline A: Factor A & 991.6937781 & 2 & 495.8468891 & 4.012 & $0.0221^{*}$ \\
error [WC] & 9269.8446834 & 75 & 123.5979291 & & \\
\hline Total & 10261.5384615 & 77 & & & \\
\hline
\end{tabular}

$+p<.10,{ }^{*} p<.05,{ }^{* *} p<.01,{ }^{* * *} p<.005,{ }^{* * * *} p<.001$.

Table 3

Ryan's Method

\begin{tabular}{lccccc}
\hline pair & $r$ & nominal level & $t$ & $p$ & sig. \\
\hline Classes A and B & 2 & 0.0333333 & 0.418 & 0.6772788 & n.s. \\
Classes A and C & 2 & 0.0333333 & 2.013 & 0.0476776 & n.s. \\
Classes B and C & 3 & 0.0166667 & 2.662 & 0.0095057 & s. \\
\hline
\end{tabular}

MSe $=123.597929, d f=75$, significance level $=0.050000$.

However, Table 3 shows that only the interaction between Classes B and C is significant $(p=0.0095)$. There is no significant difference between Classes $\mathrm{A}$ and $\mathrm{B}(p=0.677)$.

\section{London}

Although pre-questioning seemed to be more effective than vocabulary preteaching, based on the mean scores shown in Table 4, this is only the case 
Table 4

Table of Analysis of Variance 1

\begin{tabular}{llll}
\hline & mean & $S D$ & $n$ \\
\hline Class A (pre-intermediate) & 82.750 & 13.427 & 20 \\
Class B (pre-intermediate) & 84.148 & 12.637 & 27 \\
Class C (upper-intermediate) & 86.710 & 16.203 & 31 \\
\hline
\end{tabular}

Classes $\mathrm{A}$ and $\mathrm{C}$ : vocabulary pre-teaching.

Class B: pre-questioning.

Table 5

Table of Analysis of Variance 2

\begin{tabular}{lrrrrr}
\hline source & \multicolumn{1}{c}{ SS } & $d f$ & MS & $F$ & $p$ \\
\hline A: Factor A & 208.5708804 & 2 & 104.2854402 & 0.487 & $0.6163^{*}$ \\
error [WC] & 16055.5445042 & 75 & 214.0739267 & & \\
\hline Total & 16264.1153846 & 77 & & & \\
\hline
\end{tabular}

$+p<.10,{ }^{*} p<.05,{ }^{* *} p<.01,{ }^{* * *} p<.005,{ }^{* * * *} p<.001$.

when the two pre-intermediate classes (Classes A and B) are compared. When the differing levels of English proficiency are taken into account, the students in Class C (upper-intermediate), who carried out the vocabulary strategy, scored higher than those in Class B (pre-intermediate), who performed the pre-questioning strategy. In terms of the significance level, however, none of the interactions is considered significant $(p=0.6163)$. Therefore, Ryan's method was not applicable.

Table 6

Table of Analysis of Variance 1

\begin{tabular}{lccc}
\hline & mean & $S D$ & $n$ \\
\hline Class A (pre-intermediate) & 73.000 & 13.077 & 20 \\
Class B (pre-intermediate) & 59.259 & 19.231 & 27 \\
Class C (upper-intermediate) & 89.032 & 14.223 & 31 \\
\hline
\end{tabular}

Classes $A$ and $C$ : pre-questioning.

Class B: vocabulary pre-teaching. 
Table 7

Table of Analysis of Variance 2

\begin{tabular}{lcrrrc}
\hline source & SS & $d f$ & $M S$ & $F$ & $p$ \\
\hline A: Factor A & 12862.3086113 & 2 & 6431.1543057 & 24.514 & $0.0000^{*}$ \\
error [WC] & 19676.1529271 & 75 & 262.3487057 & & \\
\hline Total & 32538.4615385 & 77 & & & \\
\hline
\end{tabular}

$+p<.10,{ }^{*} p<.05,{ }^{* *} p<.01,{ }^{* * *} p<.005,{ }^{* * * *} p<.001$.

Table 8

Ryan's method

\begin{tabular}{lccccc}
\hline pair & $r$ & nominal level & $t$ & $p$ & sig. \\
\hline Classes A and B & 2 & 0.0333333 & 2.876 & 0.0052473 & s. \\
Classes A and C & 2 & 0.0333333 & 3.451 & 0.0009201 & s. \\
Classes B and C & 3 & 0.0166667 & 6.983 & 0.0000000 & s. \\
\hline
\end{tabular}

MSe $=262.348706, d f=75$, significance level $=0.050000$.

\section{DNA}

The statistics for the passage about DNA are shown in Tables 6-8. The relevant mean scores presented in Table 6 indicate that pre-questioning was more effective than vocabulary pre-teaching for the participants in this study. Classes $\mathrm{A}$ and $\mathrm{C}$, who performed the pre-questioning strategy, did better on the comprehension test. The results of Ryan's method in Table 8 show that all three interactions are significant.

\section{Google}

An inspection of the mean scores shows that for the differing levels of English proficiency, pre-questioning did not seem to be significantly effective. Table 9 shows that the students in Class B (pre-intermediate), who performed the pre-questioning strategy, scored lower than the students in Class C (upperintermediate), who carried out the vocabulary strategy. However, Table 11 indicates that the interaction between Classes B and $C$ is not significant, but that there is a significant difference between Classes A and C. Based on the results, it can be posited that although pre-questioning works better than vocabulary pre-teaching, it cannot override the effects of a linguistic ceiling. 
Table 9

Table of Analysis of Variance 1

\begin{tabular}{lccc}
\hline mean & $S D$ & $n$ & \\
\hline Class A (pre-intermediate) & 74.000 & 19.079 & 20 \\
Class B (pre-intermediate) & 80.741 & 12.744 & 27 \\
Class C (upper-intermediate) & 85.806 & 11.577 & 31 \\
\hline
\end{tabular}

Classes $A$ and $C$ : vocabulary pre-teaching.

Class B: pre-questioning.

Table 10

Table of Analysis of Variance 2

\begin{tabular}{lrrrrr}
\hline source & SS & $d f$ & $M S$ & $F$ & $p$ \\
\hline A: Factor A & 1697.9248231 & 2 & 848.9624115 & 4.025 & $0.0219^{*}$ \\
error [WC] & 15820.0238949 & 75 & 210.9336519 & & \\
\hline Total & 17517.9487179 & 77 & & & \\
\hline
\end{tabular}

$+p<.10,{ }^{*} p<.05,{ }^{* *} p<.01,{ }^{* * *} p<.005,{ }^{* * * *} p<.001$.

Table 11

Ryan's method

\begin{tabular}{lccccc}
\hline pair & $r$ & nominal level & $t$ & $p$ & sig. \\
\hline Classes A and B & 2 & 0.0333333 & 1.573 & 0.1198829 & n.s. \\
Classes A and C & 3 & 0.0166667 & 2.834 & 0.0058968 & s. \\
Classes B and C & 2 & 0.0333333 & 1.325 & 0.1891936 & n.s. \\
\hline
\end{tabular}

MSe $=123.597929, d f=75$, significance level $=0.050000$.

\section{Follow-Up Survey}

Three weeks after they read the fourth passage, the students were asked to answer a three-item questionnaire. Questions 1 and 2 sought their preference as to the two pre-reading strategies and the four passages. Question 3 required them to write whatever they remembered about each passage. The students were told that Question 3 was conducted as a post-test, just to mo- 
tivate them, and that therefore the scores did not affect their grades. As for Questions 1 and 2, they were free to answer them, and thus their answers had no influence on their grades. The questionnaire is in Appendix B.

Contrary to the test results shown in Tables 1-11, more than half the students in all three classes felt that they understood the passages more easily when they learned the key vocabulary first. This tendency is stronger in the upper-intermediate class than in the two pre-intermediate classes. It can be said that students with higher English proficiency were more likely to prefer vocabulary pre-teaching. Table 12 shows the students' preference as to which pre-reading strategy was more helpful.

Table 13 indicates that students' interest in a passage seemed to affect their understanding of it. As shown in Table 13, more than half the students in all three classes said that they were interested in the passage about Google, and DNA seemed to be the least popular topic among them. In both passages, the comprehension questions were open-ended: the students were required to write an answer in their own words. As can be seen in Tables 6 and 9, the pre-intermediate students in Classes A and B did better on the Google passage than on the DNA passage. The students in Class $C$ gained a slightly

Table 12

Students' Preference as to Pre-reading Strategies

\begin{tabular}{lcc}
\hline & Vocabulary pre-teaching & Pre-questioning \\
\hline Class A (pre-intermediate) & $11(55.0 \%)$ & $9(45.0 \%)$ \\
Class B (pre-intermediate) & $17(63.0 \%)$ & $10(37.0 \%)$ \\
Class C (upper-intermediate) & $20(64.5 \%)$ & $11(35.5 \%)$ \\
\hline Total & $48(61.5 \%)$ & $30(38.5 \%)$ \\
\hline
\end{tabular}

Table 13

Students' Interests in Topics

\begin{tabular}{lcccc}
\hline & X-rays & London & DNA & Google \\
\hline Class A (pre-intermediate) & $6(30.0 \%)$ & $5(25.0 \%)$ & $3(15.0 \%)$ & $13(65.0 \%)$ \\
Class B (pre-intermediate) & $6(22.2 \%)$ & $4(14.8 \%)$ & $4(14.8 \%)$ & $18(66.7 \%)$ \\
Class C (upper-intermediate) & $6(19.4 \%)$ & $3(9.7 \%)$ & $3(9.7 \%)$ & $24(77.4 \%)$ \\
\hline Total & $18(23.1 \%)$ & $12(15.4 \%)$ & $10(12.8 \%)$ & $55(70.5 \%)$ \\
\hline
\end{tabular}


lower mean score on the Google passage (85.806 compared with 89.032 on the DNA passage), but their percentage of correct answers was more than $85 \%$ on both passages. Therefore, it seems that they fully understood the two passages. On the other hand, the comprehension questions for the passages about X-rays and London were true/false questions. As Table 13 shows, a total of 18 students $(23.1 \%)$ said that the passage about X-rays was interesting, and 12 students $(15.4 \%)$ said that they were interested in London. From the mean scores shown in Tables 1 and 4, it is apparent that all the participants regardless of their English proficiency performed better on the X-rays passage than on the London passage.

With regard to Question 3, it is worth noting that the students who preferred pre-questioning tended to describe the content of each passage more accurately. Of the 47 students in the two pre-intermediate classes, 10 (21.3\%) could not remember anything about the four passages. Seven of the 10 $(70.0 \%)$ said that they understood the passages more easily after learning the key vocabulary. As for the upper-intermediate class, six of 31 students (19.4\%) could remember little or nothing about the content of the four passages. Of those six, five $(83.3 \%)$ said that learning the key vocabulary beforehand was more helpful for them to understand the passages.

Interestingly, 14 students wrote information that they did not gain from the passages. For example, seven upper-intermediate students and six preintermediate students wrote "DNA is used for cloning." Although this is correct information, it did not appear in the passage that they had read. When they read about DNA, Classes A and C carried out the pre-questioning strategy, and Class B learned the key vocabulary. So the students in Classes A and $C$ may have found the extra information on the Internet. However, five of the six pre-intermediate students were in Class B and thus must have obtained this information somewhere else. Another pre-intermediate student who studied architecture wrote, "London has a lot of buildings made of brick." Although what he wrote is correct, there was no information about architecture in the passage. He used the vocabulary strategy when he read about London and thus plainly had obtained the information beforehand.

It is also interesting that the test results shown in Tables 1-11 do not match how much the students remembered about the content of the four passages at the time of the follow-up survey. For example, in the upper-intermediate class were four students whose percentage of correct answers was lower than $80 \%$. However, none was among the six students who in the survey remembered little or nothing about the content of the passages: in fact their survey responses indicated that these four students accurately remembered the content of the passages. None of these four students said that they preferred vocabulary preteaching. All said that the pre-questioning strategy was more helpful.

As for the two pre-intermediate classes, altogether 18 students had scores with lower than $80 \%$ correct answers. Five of the $18(27.8 \%)$ could not re- 
member anything about the content of the passages when asked in the survey three weeks later. Ten of the 18 students $(55.6 \%)$ said that vocabulary preteaching helped them understand the passages, and eight (44.4\%) said that they preferred the pre-questioning strategy. However, of the five students who performed poorly in the reading comprehension tests and then could remember nothing about the content of the passages, none said that pre-questioning was more helpful. All said that they preferred the vocabulary strategy.

When fluent native speakers encounter a new vocabulary item in a passage, they skip over it, figuring out what it means from the context. In this case, however, they understood the passage, but arguably they did not actually learn the new words or phrases. Similarly, as the test results show, the students understood the passage more accurately when they carried out the prequestioning strategy. However, it seems that they felt as if they had learned something when they were taught the key vocabulary before reading the passage. As a result, it seems that they had an illusion that the vocabulary strategy helped them to understand the passage.

From the above analysis, we can conclude that pre-questioning is a better pre-reading strategy, but that a vocabulary strategy may be effective as a postreading strategy. The result of the questionnaire suggests that the students were more likely to be satisfied if they learned the key vocabulary. In addition, as Carrasquillo and Rodriguez (2002) pointed out, vocabulary problems due to insufficient background knowledge can occur in students' first and second languages. "The lack of prior knowledge, which is often academically based, also negatively impacts on the vocabulary background related to the topic" (p. 96). So it may be easier for students to learn and memorize the vocabulary after learning about the story.

\section{Implications}

The present study suggests that for Japanese university students, vocabulary pre-teaching is less effective than pre-questioning. Tables 1-11 show that for the two pre-intermediate classes, members of the class that carried out the pre-questioning strategy always did better on a reading comprehension test than those in the other. These results are compatible with the Taglieber et al. (1988) study of Brazilian university students. Thus this study would suggest that in this respect, Japanese and Brazilian students are similar.

However, in the vocabulary strategy used in this study, key words and phrases were listed in order, but the comprehension questions were shuffled so that the students had to read the entire passage in order to find the clue to Question 1. Although the students were allowed to look at the vocabulary list while reading the passage, they may have been confused due to the random ordering of the questions. The pre-questioning group was able to answer the questions in order, and so they probably were not as confused as the vocabulary group while reading the passage. It is possible that if the com- 
prehension questions were presented in order for both groups, another result might emerge. Further research will be needed to clarify this point.

The present study was also consistent with Clarke's (1980) contention that a limited command of the second language produces a short circuit effect on students. Tables 1-11 show that the upper-intermediate class always scored the highest of the three. Even when one of the pre-intermediate classes performed the pre-questioning strategy and the upper-intermediate class learned the key vocabulary first, the upper-intermediate class did better on the reading comprehension test.

The present study indicates that although vocabulary pre-teaching is less effective as a pre-reading strategy, it is more likely to satisfy EFL/ESL students as this appears to be their preferred method of study. This result would suggest that it might be worth investigating whether a vocabulary strategy works well as a post-reading strategy.

When students are using a vocabulary strategy, they commonly prefer to use an electronic dictionary. Recently, higher-performance electronic dictionaries have been produced that provide not only the L1 meaning of a word, but also its pronunciation. However, sometimes there is no exact correspondence between L1 and L2 meanings. For example, in English the word naive has a negative connotation, but electronic translation dictionaries often propose several Japanese words that can be used with a positive nuance. In addition, few sample sentences can be found in dictionaries. Therefore, if students depend too much on electronic dictionaries before reading a specific passage, they might misunderstand specific vocabulary. Although using such a dictionary may be useful for pre-teaching vocabulary, this has some limitations. This is a topic that should be explored in the future.

\section{The Author}

Kei Mihara is an associate professor at Kinki University, Japan. She has been teaching English to Japanese university students since receiving her master's degree in linguistics. Her research interests include corpus linguistics, English grammar and usage, error analysis, and reading comprehension.

\section{References}

Aebersold, J.A., \& Field, M.L. (1997). From reader to reading teacher: Issues and strategies for second language classrooms. Cambridge, UK: Cambridge University Press.

Ajideh, P. (2006). Schema-theory based considerations on pre-reading activities in ESP textbooks. Asian EFL Journal, 16, Article 2. Retrieved March 1, 2011, from: http:/ /www.asian-efl-journal.com/November_2006_Vol16_Art2.pdf

Al-Issa, A. (2006). Schema theory and L2 reading comprehension: Implications for teaching. Journal of College Teaching and Learning, 3(7), 41-48.

Anderson, R.C., \& Freebody, P. (1981). Vocabulary knowledge. In J.T. Guthrie (Ed.), Comprehension and teaching: Research reviews (pp. 77-117). Newark, DE: International Reading Association. 
Bransford, J.D. (2004). Schema activation and schema acquisition: Comments on Richard C. Anderson's remarks. In R.B. Ruddell \& N.J. Unrau (Eds.), Theoretical models and processes of reading (5th ed., pp. 607-619). Newark, DE: International Reading Association.

Carrasquillo, A.L., \& Rodriguez, V. (2002). Language minority students in the mainstream classroom (2nd ed.). Bristol, UK: Multilingual Matters.

Carrell, P.L. (1983). Some issues in studying the role of schemata, or background knowledge, in second language comprehension. Reading in a Foreign Language, 1(2), 81-92.

Carrell, P.L. (1984). Schema theory and ESL reading: Classroom implications and applications. Modern Language Journal, 68, 332-343.

Carrell, P.L. (1988). Interactive text processing: Implications for ESL/second language reading classrooms. In P.L. Carrell, J. Devine, \& D.E. Eskey (Eds.), Interactive approaches to second language reading (pp. 239-259). Cambridge, UK: Cambridge University Press.

Clarke, M.A. (1980). The short circuit hypothesis of ESL reading-Or when language competence interferes with reading performance. Reprinted in P.L. Carrell, J. Devine, \& D.E. Eskey (Eds.), Interactive approaches to second language reading (pp. 114-124). Cambridge, UK: Cambridge University Press.

Hudson, T. (1982). The effects of induced schemata on the "short circuit" in L2 reading: Nondecoding factors in L2 reading performance. Language Learning, 32(1), 1-31.

Hulstijn, J.H. (2001). Intentional and incidental second language vocabulary learning: A reappraisal of elaboration, rehearsal and automaticity. In P. Robinson (Ed.), Cognition and second language instruction (pp. 258-286). Cambridge, UK: Cambridge University Press.

Lee, J.W., \& Schallert, D.L. (1997). The relative contribution of L2 language proficiency and L1 reading ability to $\mathrm{L} 2$ reading performance: A test of the threshold hypothesis in an EFL context. TESOL Quarterly, 31, 713-739.

Miciano, R.Z. (2002). Self-questioning and prose comprehension: A sample case of ESL reading. Asia Pacific Education Review, 3(2), 210-216.

Nation, I.S.P. (2001). Learning vocabulary in another language. Cambridge, UK: Cambridge University Press.

Rumelhart, D.E., \& Ortony, A. (1977). The representation of knowledge in memory. In R.C. Anderson, R.J. Spiro. \& W.E. Montague (Eds.), Schooling and the acquisition of knowledge (pp. 99-135). Hillsdale, NJ: Erlbaum.

Sharp, A. (2002). Chinese L1 schoolchildren reading in English: The effects of rhetorical patterns. Reading in a Foreign Language, 14(2), 111-135.

Soars, J., \& Soars, L. (2007). New headway pre-intermediate (3rd ed.). Oxford, UK: Oxford University Press.

Taglieber, L.K., Johnson, L.L., \& Yarbrough, D.B. (1988). Effects of prereading activities on EFL reading by Brazilian college students. TESOL Quarterly, 22, 455-472.

Zhang, X. (2008). The effects of formal schema on reading comprehension-An experiment with Chinese EFL readers. Computational Linguistics and Chinese Language Processing, 13(2), 197-214. 


\section{Appendix A. Pre-reading strategies}

\section{Class B}

$$
\text { X-rays }
$$

Name:

Translate these words or phrases into Japanese.

1. X-ray photograph

2. bones

3. by accident

4. experiment

5. hospital operations

6. be awarded

7. invention

8. computer imaging

9. criminals

10. illegal items

11. luggage

12. works of art

13. underneath

14. factories

15. faults 


\section{Classes A and C}

X-rays

Name:

Do you think these sentences are true or false?

1. X-rays were discovered by Wilhelm Roentgen in $1986 . \quad \mathrm{T} \quad \mathrm{F}$

2. The first X-ray photograph was taken by Roentgen's wife. $\mathrm{T} \quad \mathrm{F}$

3. The first X-ray machine was also invented by Roentgen. $\quad \mathrm{T} \quad \mathrm{F}$

4. It is called 'the window into the human body'. $\quad \mathrm{T} F$

5. X-rays are only used in medicine. $\quad \mathrm{T} \quad \mathrm{F}$

\section{Classes A and C}

\section{London}

Name:

Translate these words or phrases into Japanese.

1. cosmopolitan

2. diverse

3. host

4. nationalities

5. bank holidays

6. fluency

7. character

8. advantages

9. leave you alone

10. be free to 
11. enthusiasm

12. principles

13. city centre

14. can afford it

\section{Class B}

London

Name:

Do you think these sentences are true or false?

1. London is more cosmopolitan than Toronto.

2. New York is the most diverse city ever.

T F

3. Londoners don't work as hard as people in other cities. $\quad$ T F

4. Immigrants want their children to learn English. $\quad T \quad F$

5. Londoners are the friendliest people in the world. $\quad \mathrm{T} \quad \mathrm{F}$

6. Londoners only like eating English food. $\quad$ T F

7. Most Londoners want to leave the city eventually. $\quad$ T F

\section{Class B}

\section{DNA}

Name:

Translate these words or phrases into Japanese.

1. contain

2. structure 
3. the Nobel Prize for Medicine

4. be left by

5. a criminal

6. be committed

7. be matched with

8. a suspect

9. be guilty

10.3 billion

11. chemical letters

12. work on

13. cure for

14. diseases

Classes A and C

DNA

Name:

Answer the questions.

1. Who made the discovery?

2. How long did it take to develop?

3. Were there any problems in the beginning? 
4. How useful is the discovery now? Give an example.

5. What could happen with it in the future?

\section{Classes A and C}

\section{Google}

Name:

Translate these words or phrases into Japanese.

1. search engine

2. be invented by

3. science fiction

4. TV programme

5. dream of -ing

6. in seconds

7. be based on

8. cheque

9. 1 followed by a hundred zeros

10. worldwide

11. accurate

12. more questions have been answered by Google than any other Internet service 


\section{Class B}

\section{Google}

Name:

Answer the questions.

1. Who made the invention?

2. How long did it take to develop?

3. Were there any problems in the beginning?

4. How useful is the invention now? Give an example.

5. What could happen with it in the future? 


\title{
Appendix B. Questionnaire
}

\author{
Classes $A, B$, and $C$
}

Questionnaire

Name:

1. Which do you prefer? Which do you think helped you understand the passage more? Choose (A) or (B).

(A) Learning the key vocabulary first and then reading the passage

(B) Looking at the comprehension questions and guessing the answers first and then reading the passage

2. Which topics did you find interesting? You can choose two or more.
(A) X-rays
(B) London
(C) DNA
(D) Google

3. Do you still remember the content of the passages? If you do, please write whatever you remember about each passage.

(A) X-rays:

(B) London:

(C) DNA:

(D) Google: 